\title{
Implementasi Metode Item-Based Collaborative Filtering dalam Pemberian Rekomendasi Calon Pembeli Aksesoris Smartphone
}

\author{
Bondan Prasetyo ${ }^{1}$, Hanny Haryanto ${ }^{2}$, Setia Astuti $^{3}$, Erna Zuni Astuti ${ }^{4}$, Yuniarsi Rahayu ${ }^{5}$ \\ Jurusan Teknik Informatika \\ Universitas Dian Nuswantoro \\ Semarang, Indonesia \\ e-mail: ${ }^{1}$ p.bondann@gmail.com, ${ }^{2}$ hanny.haryanto@dsn.dinus.ac.id, ${ }^{3}$ setia.astuti@dsn.dinus.ac.id, \\ ${ }^{4}$ erna.zuni.astuti@dsn.dinus.ac.id, 5yuniarsi.rahayu@dsn.dinus.ac.id \\ Diajukan: 11 Mei 2019; Direvisi: 10 Juli 2019; Diterima: 11 Juli 2019
}

\begin{abstract}
Abstrak
Flazzstore merupakan sebuah toko yang bergerak dibidang penjualan casing smartphone. Terdapat banyak produk yang berbeda-beda dengan banyak tema yang berbeda pula, hal ini membuat beberapa user kesulitan dalam menentukan pilihan mengenai produk yang akan dipilih. Perlunya sebuah sistem rekomendasi yang mampu memberikan rekomendasi produk kepada user, untuk memudahkan user dalam memilih produk yang akan dibelinya. Penelitian ini menggunakan metode Item-Based Collaborative Filtering, metode ini mencari similarity/kesamaan item dengan item lainnya. Sistem akan mencari rating tiap item dan menghitung nilai similarity menggunakan persamaan pearson correlation-based similarity. Kemudian nilai dari hasil perhitungan similarity akan digunakan untuk menghitung nilai prediksi tiap produk dengan menggunakan persamaan weighted average of deviation. Sebelum direkomendasikan kepada pelanggan dari hasil prediksi tersebut dihitung nilai Mean Absolute Error (MAE) dihitung selisih antara nilai rating sebenarnya dengan prediksi, dan kemudian diurutkan mulai dari terkecil ke terbesar untuk direkomendasikan kepada user. Hasil dari penelitian menunjukkan kecilnya nilai rata-rata MAE 0,572039 namun untuk proses eksekusi, waktu yang dibutuhkan cukup lama yaitu 6,4 detik. Penelitian berikutnya dapat mengombinasikan pendekatan metode content based filtering dan collaborative filtering atau disebut dengan Item Based Clustering Hybrid Method (ICHM) supaya hasil yang diperoleh lebih baik dan dapat mempersingkat waktu yang dibutuhkan.
\end{abstract}

Kata kunci: Sistem Rekomendasi, Toko Online, Item-Based Collaborative Filtering.

\begin{abstract}
Flazzstore is a shop engaged in the sale of smartphone case. There are many different products with many different themes, this makes it difficult for some users to make choices about the product to be chosen. The need for a recommendation system that is able to provide product recommendations to users, to make it easier for users to choose the product they want to buy. This study uses the Item-Based Collaborative Filtering method, this method looks for similarity items with other items. The system will search for the rating of each item and calculate the similarity value using the Pearson Correlation-Based Similarity equation. Then the value from the similarity calculation will be used to calculate the predicted value of each product by using the Weighted Average of Deviation equation. Before being recommended to customers from the prediction results, Mean Absolute Error (MAE) value is calculated as the difference between the actual rating and the prediction and then sorted from the smallest to the biggest to be recommended to the user. The results of the study show the small average value of MAE is 0.572039 but for the execution process, the time taken is quite long, that is 6.4 seconds. The future works can combine the approach of content based filtering and collaborative filtering methods or called the Item Based Clustering Hybrid Method (ICHM) so that the results obtained are better and can shorten the time needed.
\end{abstract}

Keywords: Recommendation System, Online Shop, Item-Based Collaborative Filtering. 


\section{Pendahuluan}

Kemajuan teknologi internet menjadi faktor yang mempengaruhi pertumbuhan $e$-commerce pada saat ini. Internet adalah sistem atau jaringan yang menyatukan komputer secara global, memungkinkan untuk terjadinya suatu interaksi dan komunikasi antara satu dan lainnya. Manfaat dari menghubungkan internet dan jaringan komputer yaitu perusahaan, konsumen atau rekan bisnis dapat menjalin hubungan bisnis secara efektif. E-commerce sekarang ini telah banyak digunakan oleh pebisnis seperti online shop. Pada tahun 2015, hasil penelitian eMarketer menyebutkan jika total penjualan e-commerce dunia telah mencapai \$1.771 miliar, angka ini diprediksi akan terus meningkat hingga \$2.053 milyar pada tahun 2016 ini [1]. Di Indonesia sendiri, industri e-commerce di prediksi akan mencapai angka \$130 miliar (sekitar Rp. 1738 triliun) di tahun 2020 [1]. Pada Peringatan Hari Belanja Online Nasional terakhir yang dilaksanakan 10-12 Desember 2015 sekitar 140 situs belanja Online berpartisipasi, di antaranya sebut saja Tokopedia, Blibli, Lazada, Bukalapak, hingga MatahariMall. Berdasarkan survei Nielsen terhadap 700 pengguna internet di Indonesia yang terbagi di 19 kota besar selama tiga hari transaksi tersebut mencapai Rp 2,1 triliun [2].

Flazzstore berdiri sejak tahun 2014 dan sampai sekarang sudah memiliki karyawan sebanyak 11 orang. Flazzstore merupakan sebuah toko yang menyediakan berbagai macam merek casing smartphone. Ada berbagai macam merek casing smartphone yang dijual oleh Flazzstore seperti Apple, Samsung, Vivo, Oppo, Xiaomi, Asus, dan Sony. Dari bermacam-macam merek tersebut, terdapat 59 jenis casing smartphone. Tiap jenis casing smartphone memiliki ribuan macam desain. Banyaknya varian casing dan ribuan desain tersebut membuat user membutuhkan waktu untuk menentukan pilihannya. Persoalan lain yang banyak bermunculan sekarang ini bukan pada keamanan jual beli secara online tetapi lebih kepada perilaku konsumen yang takut pada barang yang diterimanya, apa barang tersebut sesuai dengan gambar, Sesuai dengan spesifikasi yang di jelaskan, dan apa sesuai harganya dengan yang ada pada toko-toko konvensional. Selain faktor tersebut, sebagian besar konsumen adalah kelas menengah ke atas. Kelas menengah ke atas memiliki gaya hidup praktis dan sebagian besar adalah pekerja yang tidak banyak memiliki waktu luang. Agar memudahkan user untuk memilih produk yang diinginkan dan tidak memakan waktu yang terlalu lama, maka dari itu diperlukan sistem rekomendasi pada e-commerce penjualan aksesoris smartphone ini. Sistem rekomendasi adalah sistem atau teknik yang digunakan untuk merekomendasikan barang ke penggunanya. Rekomendasi tersebut berkaitan dengan berbagai cara pengambilan keputusan untuk barang apa yang akan dibeli [3]. Collaborative Filtering merupakan salah satu algoritma yang bisa diaplikasikan ke dalam sistem rekomendasi tersebut.

Rekomendasi collaborative filtering adalah teknik yang paling banyak digunakan pada sistem rekomendasi [4]. Sistem rekomendasi ini dikembangkan untuk menutupi kelemahan dari metode content based filtering yang hanya bersumber pada konten sehingga para pengguna tidak bisa mendapatkan rekomendasi untuk jenis konten yang lainnya [4]. Collaborative Filtering mempunyai cara kerja dengan menambahkan suatu pilihan atau rating dari sebuah produk, untuk menemukan pola pengguna bisa dilihat dari history yang di-rating oleh pengguna, dan menciptakan sebuah rekomendasi baru yang dibandingkan pada pola pengguna lainnya. Poin rating biasanya berbentuk voting atau binary [5]. Penelitian ini menerapkan metode Item-Based Collaborative Filtering untuk melakukan rekomendasi pemilihan barang pada e-commerce. E-commerce pada penelitian ini bergerak di bidang penjualan aksesoris smartphone.

Dalam penelitian [6] merekomendasikan paket pembelian barang kepada pelanggan dengan metode collaborative filtering agar pelanggan tersebut merasa puas terhadap toko online, serta untuk meningkatkan omset penjualan. Didukung dengan teknik link analisis dapat membantu menentukan rekomendasi dengan profil pengguna. Penelitian ini menyimpulkan bahwa semakin besar nilai confidence, maka strong association rule akan semakin baik. Penelitian yang dilakukan oleh [7] menerapkan Item Collaborative Filtering untuk rekomendasi pembelian buku secara online. Sistem rekomendasi tersebut bersumber pada kesamaan antara pemberian barang yang di-rating dengan barang yang dibeli. Pada toko buku online yang menerapkan sistem rekomendasi berhasil merekomendasikan buku ke pelanggan sesuai dengan pelanggan yang memberikan rating terhadap buku yang diminati oleh pelanggan tersebut. [8] dalam penelitiannya membahas sistem rekomendasi buku pada metode collaborative filtering dengan cara melihat kedekatan buku yang bersumber pada nilai di-rating. Namun saat diaplikasikan ke buku yang sama sekali belum pernah di-rating memang metode ini kurang begitu sempurna. Hal ini ditunjukkan dari nilai ratarata Mean Absolut Error (MAE) yang ditunjukkan pada uji coba $1(1,064)$ lebih kecil daripada uji coba 2 $(1,21)$, uji coba $4(2,474)$ dan uji coba $5(3,526)$. Kemudian, penelitian yang dilakukan oleh [9] yang melakukan perancangan sistem rekomendasi pakaian distro dengan menggunakan Item Collaborative Filtering yang bersumber pada jumlah penjualan atau jumlah pembelian dan dikategorikan setiap produk agar memudahkan para pelanggan dalam memilih suatu pakaian. Peneliti menyarankan untuk menambahkan fitur pada proses pendaftaran dengan memanfaatkan teknologi saat ini. Misal dengan

Jurnal Eksplora Informatika Vol. 9, No. 1, September 2019. 
menggunakan SMS pada telepon seluler untuk melakukan pendaftaran. Dari penelitian-penelitian tersebut dapat dilihat bahwa Collaborative Filtering dapat memberikan performa rekomendasi dengan baik, namun ada permasalahan ketika data yang digunakan minim, seperti yang terjadi pada rekomendasi buku yang belum ada atau jarang rating-nya. Untuk memecahkan masalah tersebut, penelitian ini akan mengukur performa dari Collaborative Filtering dengan cara menyeleksi data yang bersumber pada konsumen yang memiliki kesamaan karakteristik, sehingga dapat memberikan sebuah informasi baru kepada konsumen dan asumsinya dapat bekerja dengan kondisi data dengan rating yang minim, karena yang diberikan oleh sistem merupakan informasi yang bersumber pada pola satu kelompok konsumen yang hampir sama.

\section{Metode Penelitian}

A. Collaborative Filtering

Metode collaborative filtering ini menyeleksi data bersumber pada konsumen yang memiliki kesamaan karakteristik, sehingga dapat memberikan sebuah informasi baru kepada konsumen. Karena yang diberikan oleh sistem merupakan informasi yang bersumber pada pola satu kelompok konsumen yang hampir sama [10]. Ide utama dalam sistem rekomendasi collaborative filtering adalah untuk memanfaatkan opini user lain yang ada untuk memprediksi item yang mungkin akan disukai/diminati oleh seorang user.

Nilai rekomendasi yang diberikan dengan memanfaatkan metode ini bergantung pada opini user lain (neighbor) terhadap suatu item. Belakangan diketahui bahwa melakukan reduksi neighbor (yaitu dengan memotong neighbor sehingga hanya beberapa user yang memiliki kesamaan/similiarity tertinggi sajalah yang akan digunakan dalam perhitungan) mampu meningkatkan kualitas rekomendasi yang diberikan [11].

Collaborative Filtering terbagi menjadi dua kelas yaitu item-based dan user-based [10].

1. Item-to-Item Collaborative Filtering

Metode rekomendasi yang bersumber pada kemiripan antara pemberi rating terhadap suatu produk dengan produk yang akan dibeli. Dilihat dari tingkat kemiripan produk yang kemudian dibagi dengan parameter kebutuhan pelanggan agar memperoleh nilai kegunaan produk. Produk yang akan dijadikan rekomendasi adalah produk yang memiliki nilai kegunaan tertinggi [12]. Metode rekomendasi ini digunakan sebagai saran untuk beberapa permasalahan yang ada pada user-based collaborative filtering yakni skalabilitas dan keterbatasan serta masalah memori dan waktu.

2. User-Based Collaborative Filtering

Suatu algoritma yang memanfaatkan teknik statistika untuk mendapatkan sekelompok pengguna, atau disebut sebagai neighbor. Setelah sekelompok neighbor terbentuk, sistem memanfaatkan algoritma yang berbeda untuk menggabungkan minat neighbors yang menghasilkan rekomendasi N-teratas untuk active user atau prediksi.

\section{B. Pearson Correlation Based Similarity}

Metode pearson correlation based similarity adalah metode perhitungan yang berdasarkan pada korelasi yang paling banyak diaplikasikan untuk perhitungan nilai similarity, yang ditunjukkan pada persamaan (1). Korelasi pearson menilai dari berapa besar hubungan linear antara dua variabel. Koefisien korelasi Pearson berasal dari model regresi linier yang memiliki asumsi yaitu bahwa hubungan antara dua variabel harus linier, dengan kesalahan harus independen dan memiliki distribusi probabilitas dengan mean 0 dan varians (berdistribusi Normal $(0,1)$. [13]

Berikut ini adalah persamaan metode pearson correlation-based similarity:

$$
\operatorname{sim}(k, l)=\frac{\sum_{u=1}^{m}\left(R_{u, k}-\bar{R}_{k}\right)\left(R_{u, l}-\bar{R}_{l}\right)}{\sqrt{\sum_{u=1}^{m}\left(R_{u, k}-\bar{R}_{k}\right)^{2}} \sqrt{\sum_{u=1}^{m}\left(R_{u, l}-\bar{R}_{l}\right)^{2}}}
$$

Dimana $\operatorname{sim}(k, l)$ adalah nilai similarity antara item $\mathrm{k}$ dan item $1, \bar{R}_{k}$ dan $\bar{R}_{l}$ adalah rating rata-rata pada item $\mathrm{k}$ dan item $1, \mathrm{R}_{\mathrm{u}, \mathrm{k}}$ dan $\mathrm{R}_{\mathrm{u}, \mathrm{l}}$ adalah rating oleh user $\mathrm{u}$ kepada item $\mathrm{k}$ dan item $\mathrm{l}$ dan $m$ adalah jumlah total user.

\section{Prediksi Collaborative}

Item yang diprediksi dihitung menggunakan metode weighted average of deviation yang didapat dari rata-rata item yang telah di-rating merupakan metode yang digunakan untuk prediksi rating pada item $\mathrm{k}$ yang telah di-rating. Rumus berikut ini merupakan perhitungan prediksi rating pada item $l$ untuk $u$ ser $u$. 


$$
P_{u, k}=\bar{R}_{k}+\frac{\sum_{l=1}^{n}\left(R_{u, l}-\bar{R}_{l}\right) \times \operatorname{sim}(k, l)}{\sum_{l=1}^{n}|\operatorname{sim}(k, l)|}
$$

Persamaan (2) menunjukkan di mana $P_{u, k}$ adalah prediksi rating item k untuk user u, $n$ adalah jumlah user, $\bar{R}_{k}$ adalah rating rata-rata pada item $\mathrm{k}, \bar{R}_{l}$ adalah rating rata-rata pada item 1 dan $R_{u, l}$ adalah rating diberikan user u kepada item 1 . $\operatorname{Sim}(k, l)$ adalah nilai similarity antara item $\mathrm{k}$ dengan seluruh rated item ke-l.

\section{Mean Absolute Error}

Hasil keakuratan sistem rekomendasi untuk menentukan tingkat akurasi ditentukan oleh nilai error yang dihasilkan. Penelitian ini menggunakan persamaan MAE (Mean Absolute Error) yang ditunjukkan pada persamaan (3). Persamaan ini termasuk jenis statistical accuracy metrics di mana MAE akan menghitung nilai rata-rata selisih Antara nilai prediksi dengan nilai yang sebenarnya [14].

$$
M A E=\frac{\sum_{u=1}^{N}\left|P_{u, k}-R_{u, k}\right|}{N}
$$

Di mana $P_{u, k}$ adalah Prediksi rating user u untuk item $\mathrm{k}, R_{u, k}$ adalah Nilai rating yang diberikan user u untuk item $\mathrm{k}$, dan $N$ adalah Jumlah user.

\section{E. Proses Penerapan ke Metode Item Based Collaborative Filtering}

Pada tahap ini akan menerangkan bagaimana cara menerapkan metode Item-Based Collaborative Filtering yang diimplementasikan ke produk yang dijual. Gambar 1 menunjukkan alur penerapan metode Item-Based Collaborative Filtering.

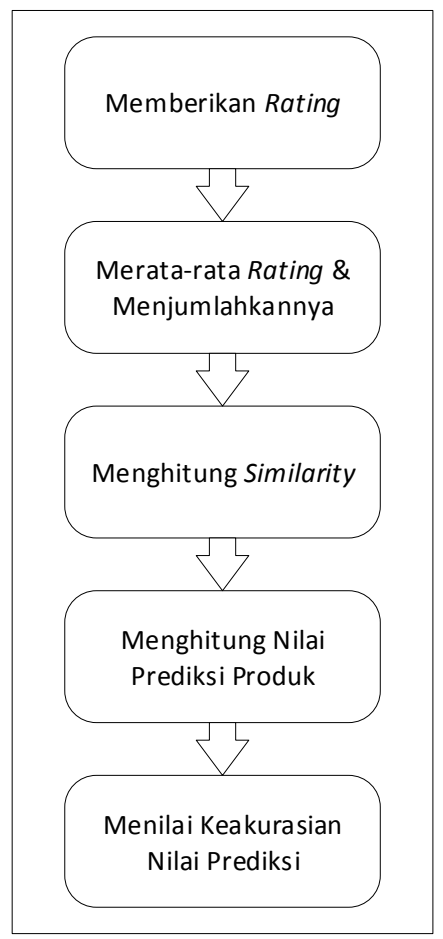

Gambar 1. Alur penerapan metode Item-Based Collaborative Filtering.

1) Tabel 1 adalah langkah pertama user memberikan penilaian rating kepada produk yang dibeli.

Tabel 1. Tabel rating pembeli terhadap produk.

\begin{tabular}{llllll}
\hline Kode Produk & User-1 & User-2 & User-3 & $\ldots$ & User-n \\
\hline Prdk_1 & $\mathrm{R}_{11}$ & $\mathrm{R}_{12}$ & $\mathrm{R}_{13}$ & $\ldots$ & $\mathrm{R}_{1 \mathrm{n}}$ \\
\hline Prdk_2 & $\mathrm{R}_{21}$ & $\mathrm{R}_{22}$ & $\mathrm{R}_{23}$ & $\ldots$ & $\mathrm{R}_{2 \mathrm{n}}$ \\
\hline Prdk_3 & $\mathrm{R}_{13}$ & $\mathrm{R}_{32}$ & $\mathrm{R}_{33}$ & $\ldots$ & $\mathrm{R}_{3 \mathrm{n}}$ \\
\hline
\end{tabular}




\begin{tabular}{llllll}
\hline Kode Produk & User-1 & User-2 & User-3 & $\ldots$ & User-n \\
\hline$\ldots$ & $\ldots$ & $\ldots$ & $\ldots$ & $\ldots$ & $\ldots$ \\
\hline Prdk_m & $\mathrm{R}_{\mathrm{m} 1}$ & $\mathrm{R}_{\mathrm{m} 2}$ & $\mathrm{R}_{\mathrm{m} 3}$ & $\ldots$ & $\mathrm{R}_{\mathrm{mn}}$ \\
\hline
\end{tabular}

Di mana User-1 - User-n adalah kode pelanggan, Prdk_1 - Prdk_m adalah kode produk dan $\mathrm{R}_{11}-\mathrm{R}_{\mathrm{nm}}$ adalah nilai rating.

2) Langkah kedua mencari nilai rata-rata rating, mencari jumlah nilai rating - (rata-rata rating) lalu dikuadratkan. Hal ini ditunjukkan pada Tabel 2.

Tabel 2. Tabel jumlah rating-(rata-rata rating) per produk.

\begin{tabular}{llllllll}
\hline Kode Produk & User-1 & User-2 & User-3 & $\ldots$ & User-n & $\overline{\mathbf{R}} \quad \sum(\mathbf{R}-\overline{\mathbf{R}})^{2}$ & $\sqrt{\sum(\mathbf{R}-\overline{\mathbf{R}})^{2}}$ \\
\hline Prdk_1 & $\mathrm{R}_{11}$ & $\mathrm{R}_{12}$ & $\mathrm{R}_{13}$ & $\ldots$ & $\mathrm{R}_{1 \mathrm{n}}$ & & \\
\hline $\operatorname{Prdk\_ 2}$ & $\mathrm{R}_{21}$ & $\mathrm{R}_{22}$ & $\mathrm{R}_{23}$ & $\ldots$ & $\mathrm{R}_{2 \mathrm{n}}$ & & \\
\hline Prdk_3 & $\mathrm{R}_{13}$ & $\mathrm{R}_{32}$ & $\mathrm{R}_{33}$ & $\ldots$ & $\mathrm{R}_{3 \mathrm{n}}$ & \\
\hline$\ldots$ & $\ldots$ & $\ldots$ & $\ldots$ & $\ldots$ & $\ldots$ & & \\
\hline Prdk_m & $\mathrm{R}_{\mathrm{m} 1}$ & $\mathrm{R}_{\mathrm{m} 2}$ & $\mathrm{R}_{\mathrm{m} 3}$ & $\ldots$ & $\mathrm{R}_{\mathrm{mn}}$ & & \\
\hline
\end{tabular}

Di mana $\overline{\mathbf{R}}$ adalah nilai rata-rata, $\sum(\mathbf{R}-\overline{\mathbf{R}})^{\mathbf{2}}$ adalah jumlah nilai rating - (rata-rata rating) lalu dikuadratkan, $\sqrt{ } \sum(\mathbf{R}-\overline{\mathbf{R}})^{2}$ adalah akar dari jumlah nilai rating - (rata-rata rating) lalu dikuadratkan.

3) Langkah ketiga menghitung similarity antar produk dengan persamaan rumus (4) di bawah ini :

$$
\operatorname{sim}(k, l)=\frac{\sum_{u=1}^{m}\left(R_{u, k}-\bar{R}_{k}\right)\left(R_{u, l}-\bar{R}_{l}\right)}{\sqrt{\sum_{u=1}^{m}\left(R_{u, k}-\bar{R}_{k}\right)^{2}} \sqrt{\sum_{u=1}^{m}\left(R_{u, l}-\bar{R}_{l}\right)^{2}}}
$$

4) Setelah nilai dari similarity antar produk diketahui, langkah selanjutnya adalah menghitung nilai prediksi produk terhadap user, lihat persamaan (5). Nilai user dan produk ditunjukkan pada Tabel 3.

$$
P_{u, k}=\bar{R}_{k}+\frac{\sum_{l=1}^{n}\left(R_{u, l}-\bar{R}_{l}\right) \times \operatorname{sim}(k, l)}{\sum_{l=1}^{n}|\operatorname{sim}(k, l)|}
$$

Tabel 3. Hasil prediksi.

\begin{tabular}{llllll}
\hline Kode Produk & User-1 & User-2 & User-3 & $\ldots$ & User-n \\
\hline Prdk_1 & $\mathrm{P}_{11}$ & $\mathrm{P}_{12}$ & $\mathrm{P}_{13}$ & $\ldots$ & $\mathrm{P}_{1 \mathrm{n}}$ \\
\hline Prdk_2 & $\mathrm{P}_{21}$ & $\mathrm{P}_{22}$ & $\mathrm{P}_{23}$ & $\ldots$ & $\mathrm{P}_{2 \mathrm{n}}$ \\
\hline Prdk_3 & $\mathrm{P}_{13}$ & $\mathrm{P}_{32}$ & $\mathrm{P}_{33}$ & $\ldots$ & $\mathrm{P}_{3 \mathrm{n}}$ \\
\hline$\ldots$ & $\ldots$ & $\ldots$ & $\ldots$ & $\ldots$ & $\ldots$ \\
\hline Prdk_m & $\mathrm{P}_{\mathrm{m} 1}$ & $\mathrm{P}_{\mathrm{m} 2}$ & $\mathrm{P}_{\mathrm{m} 3}$ & $\ldots$ & $\mathrm{P}_{\mathrm{mn}}$ \\
\hline
\end{tabular}

5) Menilai keakurasian nilai prediksi

Untuk menentukan nilai keakurasian dari sistem rekomendasi yang bersumber pada nilai Mean Absolute Error (MAE) yaitu rata-rata dari error yang sudah di absolutkan. Error tersebut diperoleh dari selisih nilai rating sebenarnya dengan nilai rating hasil prediksi. Perhitungan nilai MAE dapat ditunjukkan dengan persamaan (6) berikut ini.

$$
M A E=\frac{\sum_{u=1}^{N}\left|P_{u, k}-R_{u, k}\right|}{N}
$$

\section{Hasil dan Pembahasan}

A. Implementasi Sistem Rekomendasi

Dalam penelitian ini dilakukan percobaan dengan data yang dimasukkan sebanyak 5 user dan 6 produk dengan besarnya rating yang bervariasi. Diasumsikan ketika user mengakses website dan mengeklik salah satu produk misalnya produk JOKER VS BATMAN Z0215 iPhone 7 Case lihat Gambar 2. 


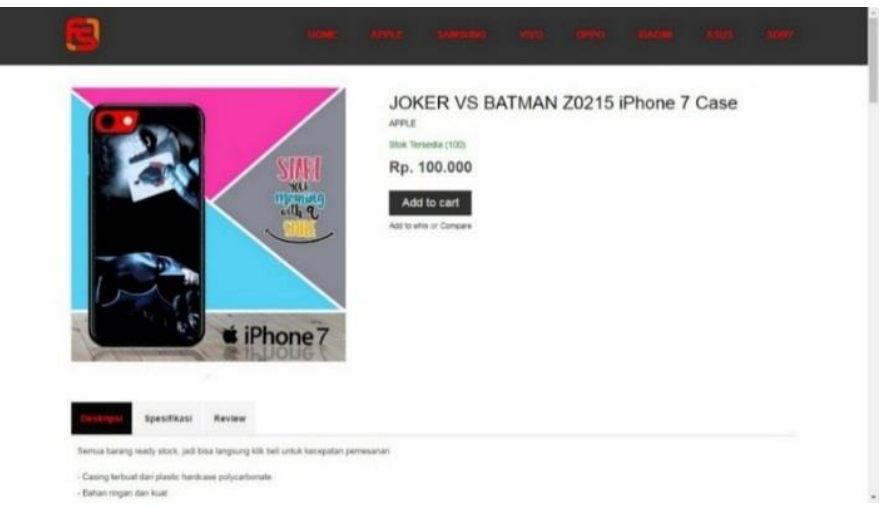

Gambar 2. Contoh produk yang dipilih oleh user.

Sistem akan mencari produk yang mempunyai kategori sama dengan produk yang dilihat oleh user dan produk yang dilihat user tidak dimasukkan ke dalam proses rekomendasi, maka akan menjadi seperti Gambar 3 di bawah ini.

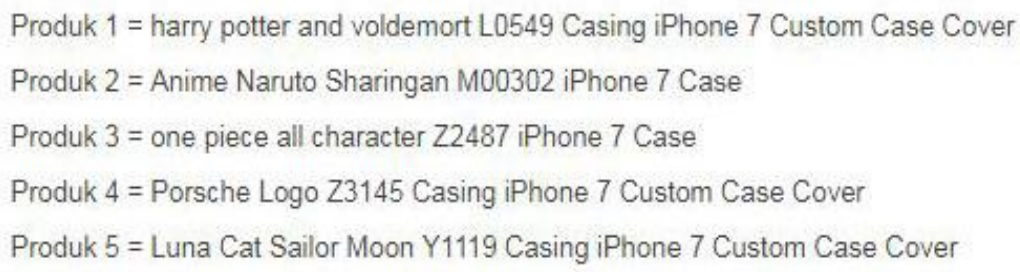

Gambar 3. Tampilan produk yang mempunyai kategori iPhone 7.

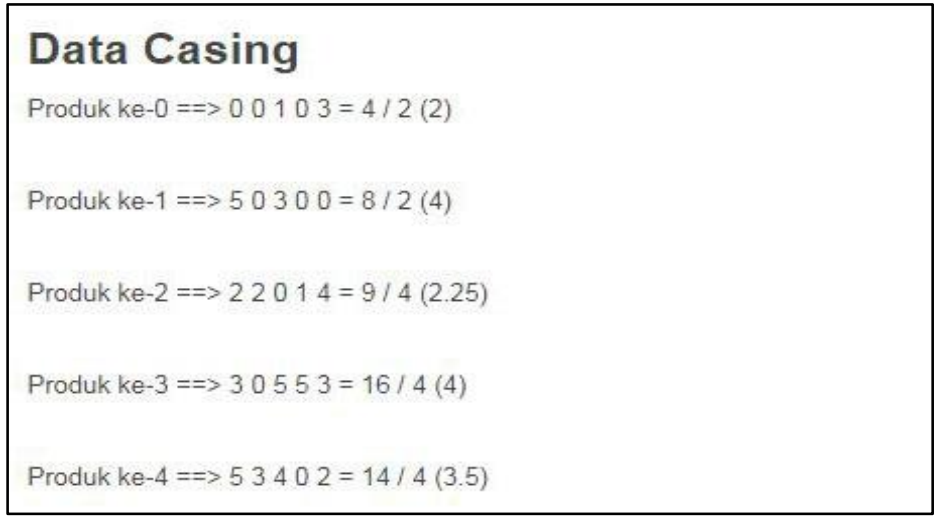

Gambar 4. Tampilan data rating dari beberapa produk.

Pada Gambar 4 merupakan data dari produk yang sudah diberi rating oleh beberapa user di mana nilai rating tersebut dibutuhkan untuk menghitung nilai similarity.

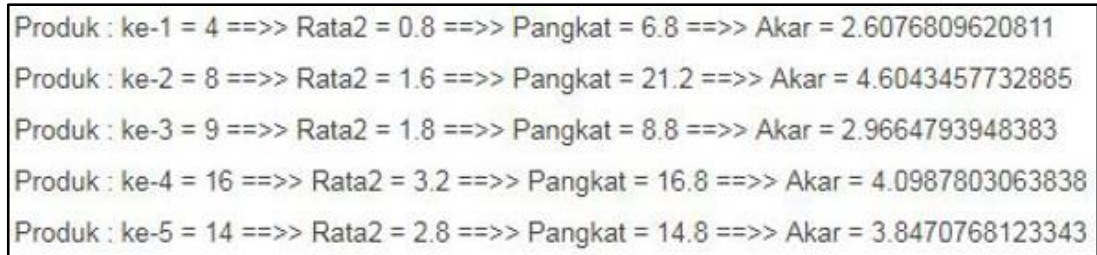

Gambar 5. Tampilan perhitungan yang diperlukan guna mencari nilai similarity. 
Gambar 5 merupakan perhitungan yang dibutuhkan untuk memudahkan dalam menghitung nilai similarity mulai dari menjumlahkan $R$ tiap produk kemudian mencari $\bar{R}$ tiap produk dan mencari nilai $\sum(\boldsymbol{R}-\bar{R})^{2}$ serta mencari $\sqrt{\sum(\boldsymbol{R}-\bar{R})^{2}}$. Pada Gambar 4 dan Gambar 5 dapat diimplementasikan pada tabel dibawah ini dan digunakan untuk penghitungan nilai similarity kedekatan antar produk berdasarkan rating pada Tabel 4 .

Tabel 4. Tabel rating pembeli terhadap produk.

\begin{tabular}{lllllllll}
\hline $\begin{array}{l}\text { Kode } \\
\text { Produk }\end{array}$ & User-1 & User-2 & User-3 & User-4 & User-5 & $\bar{R}$ & $\sum(\boldsymbol{R}-\bar{R})^{\mathbf{2}}$ & $\sqrt{\sum(\boldsymbol{R}-\bar{R})^{\mathbf{2}}}$ \\
\hline Prdk_1 & 0 & 0 & 1 & 0 & 3 & 0,8 & 6,8 & 2,607680962 \\
\hline Prdk_2 & 5 & 0 & 3 & 0 & 0 & 1,6 & 21,2 & 4,604345773 \\
\hline Prdk_3 & 2 & 2 & 0 & 1 & 4 & 1,8 & 8,8 & 2,966479395 \\
\hline Prdk_4 & 3 & 0 & 5 & 5 & 3 & 3,2 & 16,8 & 4,098780306 \\
\hline Prdk_5 & 5 & 3 & 4 & 0 & 2 & 2,8 & 14,8 & 3,847076812 \\
\hline
\end{tabular}

B. Contoh Perhitungan Similarity

Perhitungan ini menggunakan Persamaan (1). Pada contoh kasus nilai similarity ini sim(Prdk_1,Prdk_2) di mana Prdk_1 adalah Harry Potter and Voldemort L0549 Casing iPhone 7 Custom Case Cover dan Prdk_2 adalah Anime Naruto Sharingan M00302 iPhone 7 Case. $\mathrm{R}_{\mathrm{u}, \mathrm{k}}$ merupakan rating yang diberikan oleh user ke-1 sampai ke-5 pada Prdk_1 kemudian $\bar{R}_{\mathrm{k}}$ merupakan rata-rata rating Prdk_1. Dan $\mathrm{R}_{\mathrm{u}, 1}$ merupakan rating yang diberikan oleh user ke-1 sampai ke-5 pada Prdk_2 kemudian $\bar{R}_{1}$ merupakan rata-rata rating Prdk_2. Dengan contoh perhitungan sebagai berikut :

$$
\begin{aligned}
& \operatorname{Sim}\left(\operatorname{Prdk} \_1, \operatorname{Prdk} \_2\right)=\frac{(0-0,8)(5-1,6)+(0-0,8)(0-1,6)+(1-0,8)(3-1,6)+(0-0,8)(0-1,6)+(3-0,8)(0-1,6)}{\sqrt{(0-0,8)^{2}+(0-0,8)^{2}+(1-0,8)^{2}+(0-0,8)^{2}+(3-0,8)^{2}} \cdot \sqrt{(5-1,6)^{2}+(0-1,6)^{2}+(3-1,6)^{2}+(0-1,6)^{2}+(0-1,6)^{2}}} \\
& \text { Sim }\left(\operatorname{Prdk} \_1, \operatorname{Prdk} \_2\right)=\frac{(-2,72)+1,28+0,28+1,28+(-3,52)}{\sqrt{6,8} \cdot \sqrt{21,2}} \\
& \text { Sim }\left(\operatorname{Prdk} \_1, P r d k \_2\right)=-0,283176057
\end{aligned}
$$

Hasil dari perhitungan perbandingan antar produk dapat dilihat pada Tabel 5 sebagai berikut:

Tabel 5. Tabel hasil similarity antar produk

\begin{tabular}{cc}
\hline sim(Prdk_1,Prdk_1) & 1 \\
\hline sim(Prdk_1, Prdk_2) & $-0,283176057$ \\
\hline sim(Prdk_1, Prdk_3) & 0,620505228 \\
\hline sim(Prdk_1, Prdk_4) & 0,112272178 \\
\hline sim(Prdk_1, Prdk_5) & $-0,119617833$ \\
\hline sim(Prdk_2, Prdk_3) & $-0,322139077$ \\
\hline sim(Prdk_2, Prdk_4) & 0,233147147 \\
\hline sim(Prdk_2, Prdk_5) & 0,824240723 \\
\hline sim(Prdk_3,Prdk_4) & $-0,477014979$ \\
\hline sim(Prdk_3, Prdk_5) & $-0,105149946$ \\
\hline sim(Prdk_4, Prdk_5) & $-0,240989487$ \\
\hline
\end{tabular}




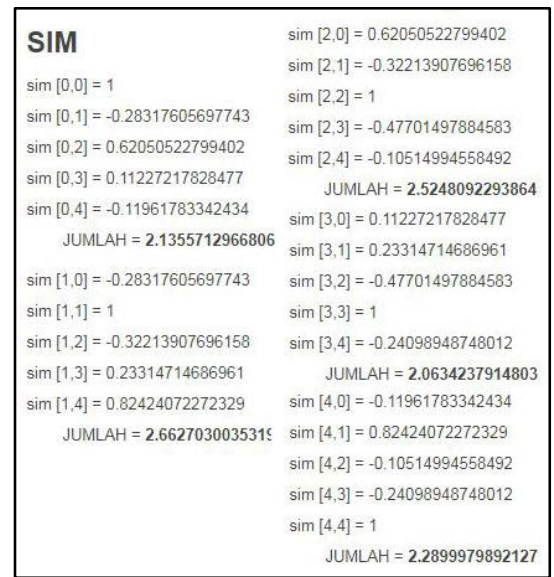

Gambar 6. Tampilan hasil similarity pada sistem.

Di dalam sistem ini nilai similarity tidak disimpan ke dalam database, tetapi langsung dihitung ketika akan melakukan rekomendasi dan hasilnya akan disimpan ke dalam suatu array. Hal ini dilakukan karena nilai similarity terus berubah-ubah ketika ada rating yang baru masuk atau user melihat barang yang lainnya.

Hal tersebut mengakibatkan waktu komputasi akan meningkat dalam setiap melakukan proses rekomendasi. Hasil dari perhitungan similarity ini nantinya akan digunakan kembali dalam proses selanjutnya yaitu menghitung prediksi.

C. Contoh Perhitungan Prediksi

Setelah diketahui nilai dari similarity antar produk, langkah selanjutnya adalah menghitung nilai prediksi produk terhadap user dengan persamaan rumus (2) weighted average of deviation. Perhitungan pada contoh kasus prediksi di mana $\mathrm{P}_{\mathrm{u} 1, \mathrm{Prdk}_{-} 1}$ adalah prediksi rating untuk user ke-1 pada produk ke-1 yaitu Prdk_1, $\bar{R}_{\mathrm{k}}$ merupakan rata-rata rating pada Prdk_1. $\bar{R}_{1}$ merupakan rata-rata rating pada produk ke-1. $\mathrm{R}_{\mathrm{u}, \mathrm{l}}$ merupakan rating yang diberikan oleh user ke-1 sampai ke-5. Dan $\operatorname{sim}(\mathrm{k}, \mathrm{l})$ adalah nilai similarity produk k yaitu Prdk_1 dan produk 1 dari ke-1 sampai ke-5. Dengan contoh perhitungan sebagai berikut :

$$
\begin{aligned}
& \mathrm{P}_{\mathrm{u} 1, \text { Prdk_1 }}=0,8+\frac{(0-0,8)(1)+(5-1,6)(-0,283)+(2-1,8)(0,620)+(3-3,2)(0,112)+(5-2,8)(-0,119)}{|1|+|(-0,283)|+|0,620|+|(0,112)|+|(-0,119)|} \\
& \mathrm{P}_{\mathrm{u} 1, \text { Prdk_1 }}=0,8+\frac{(-0.8)+(-0.9622)+0.124+(-0.0224)+(-0.2618)}{2,134} \\
& \mathrm{P}_{\mathrm{u} 1, \text { Prdk_1 }}=0,8+\frac{-1.9224}{2.134} \\
& \mathrm{P}_{\mathrm{u} 1, \text { Prdk_1 }}=-0,101
\end{aligned}
$$

Tabel 6. Tabel hasil prediksi.

\begin{tabular}{cccccc}
\hline Kode Produk & User-1 & User-2 & User-3 & User-4 & User-5 \\
\hline Prdk_1 & $-0,101075614$ & 0,516229656 & 0,212425438 & 0,656571102 & 2,715849417 \\
\hline Prdk_2 & 3,601279596 & 0,841706757 & 2,851348293 & 0,471839237 & 0,233826117 \\
\hline Prdk_3 & 1,194962633 & 2,482996665 & 0,567550228 & 1,267211717 & 3,487278756 \\
\hline Prdk_4 & 3,140537028 & 1,355272762 & 4,517373595 & 4,359979535 & 2,62683708 \\
\hline Prdk_5 & 5,038115778 & 2,680805782 & 3,710700481 & 0,890499629 & 1,67987833 \\
\hline
\end{tabular}




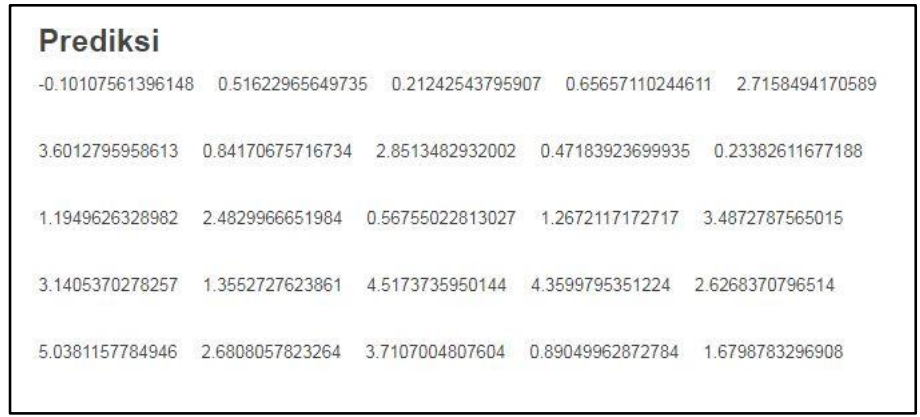

Gambar 7. Tampilan hasil prediksi pada sistem.

D. Contoh Perhitungan MAE

Langkah terakhir menghitung mean absolute error (MAE), yaitu rata-rata dari error yang di absolutkan. Di mana error merupakan selisih dari nilai rating sebenarnya dengan nilai rating hasil prediksi. Berikut pada Tabel 6 adalah perhitungan MAE yang dihitung dengan Persamaan rumus (3).

Tabel 7. Hasil MAE.

\begin{tabular}{|c|c|c|c|c|c|c|}
\hline \multirow[t]{2}{*}{ Rumus } & \multicolumn{5}{|c|}{$\left|P_{u, i}-R_{u, i}\right|$} & \multirow{2}{*}{$\sum_{u=1}^{N}\left|P_{u, i}-R_{u, i}\right|$} \\
\hline & User-1 & User-2 & User-3 & User-4 & User-5 & \\
\hline Prdk_1 & 0,101075614 & 0,516229656 & 0,787574562 & 0,656571102 & 0,284150583 & 2,345601518 \\
\hline Prdk_2 & 1,398720404 & 0,841706757 & 0,148651707 & 0,471839237 & 0,233826117 & 3,094744222 \\
\hline Prdk_3 & 0,805037367 & 0,482996665 & 0,567550228 & 0,267211717 & 0,512721244 & 2,635517221 \\
\hline Prdk_4 & 0,140537028 & 0,140537028 & 0,482626405 & 0,640020465 & 0,37316292 & 2,99161958 \\
\hline Prdk_5 & 0,038115778 & 0,319194218 & 0,289299519 & 0,890499629 & 0,32012167 & 1,857230814 \\
\hline
\end{tabular}

Penjelasan perhitungan pada kasus ini MAE Prdk_1 adalah mencari nilai Mean Absolute Error pada produk 1 . $\mathrm{P}_{\mathrm{u}, \mathrm{i}}$ merupakan rating prediksi dari user ke $1-5$ pada produk ke $1 . \mathrm{R}_{\mathrm{u}, \mathrm{i}}$ adalah rating yang diberikan oleh user ke 1-5 pada produk ke 1 dan kemudian di-absolute-kan. Demikian contoh perhitungannya:

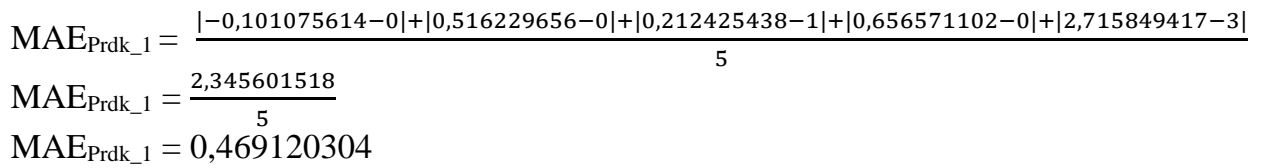

Tabel 8. Hasil MAE sebelum disortir.

\begin{tabular}{cc}
\hline Produk & MAE \\
\hline Prdk_1 & 0,469120304 \\
\hline Prdk_2 & 0,618948844 \\
\hline Prdk_3 & 0,527103444 \\
\hline Prdk_4 & 0,598323916 \\
\hline Prdk_5 & 0,371446163 \\
\hline
\end{tabular}

Dari hasil MAE pada Tabel 8 tersebut sebelum direkomendasikan kepada user di-sorting ascending terlebih dahulu atau diurutkan dari nilai terkecil ke terbesar. List produk sebelum di-sorting berdasarkan nilai MAE pada Tabel 9 sebagai berikut:

Prdk_1 = Harry Potter and Voldemort L0549 Casing iPhone 7 Custom Case Cover

Prdk_2 = Anime Naruto Sharingan M00302 iPhone 7 Case

Prdk_3 = One Piece All Character Z2487 iPhone 7 Case

Prdk_4 = Porsche Logo Z3145 Casing iPhone 7 Custom Case Cover

Prdk_5 = Luna Cat Sailor Moon Y1119 Casing iPhone 7 Custom Case Cover 
Tabel 9. Hasil MAE setelah disortir ascending.

\begin{tabular}{cc}
\hline Produk & MAE \\
\hline Prdk_5 & 0,371446163 \\
\hline Prdk_1 & 0,469120304 \\
\hline Prdk_3 & 0,527103444 \\
\hline Prdk_4 & 0,598323916 \\
\hline Prdk_2 & 0,618948844 \\
\hline
\end{tabular}

Kemudian melakukan percobaan waktu eksekusi yang dibutuhkan oleh sistem dalam proses pembuatan rekomendasi. Menghitung waktu eksekusi menggunakan peramban yang di dalamnya terdapat fasilitas untuk menghitung berapa lama waktu yang diperlukan saat memuat sebuah halaman. Percobaan dilakukan menggunakan perangkat keras Processor Intel ${ }^{\circledR}$ Celeron ${ }^{\circledR}$ Processor 1007U, RAM berkapasitas 4GB, Harddisk kapasitas 500GB, serta Modem Smartfren M2y Berdasarkan pada perhitungan peramban, lama waktu yang diperlukan adalah 6,4 detik atau 6,4 second. Hasil dari penelitian menunjukkan performa dari Collaborative Filtering dengan cara menyeleksi data yang bersumber pada konsumen yang memiliki kesamaan karakteristik menghasilkan kecilnya nilai rata-rata MAE 0,572039 yang berarti mempunyai akurasi yang baik, namun untuk proses eksekusi, waktu yang dibutuhkan cukup lama yaitu 6,4 detik.

\section{Kesimpulan}

Dalam penelitian ini telah dihasilkan performa dari Collaborative Filtering dalam melakukan rekomendasi item dengan pertimbangan data yang bersumber pada konsumen yang memiliki kesamaan karakteristik dapat menghasilkan akurasi yang baik, namun perlu ditingkatkan pada segi waktu pemrosesannya. Dengan menggunakan algoritma Item-Based Collaborative Filtering dapat diaplikasikan dalam pembuatan sistem rekomendasi pada kasus penjualan aksesoris smartphone sebagai rekomendasi untuk user cukup baik, meskipun pemberian rating minim. Dibuktikan dengan kecilnya rata-rata nilai Mean Absolute Error (MAE) yaitu 0,572039 namun untuk proses eksekusi. Dari segi waktu yang dibutuhkan cukup lama yaitu 6,4 detik atau 6,4 second. Untuk penelitian berikutnya dapat mengombinasikan pendekatan metode content based filtering dan collaborative filtering atau disebut dengan Item Based Clustering Hybrid Method (ICHM) supaya hasil yang diperoleh lebih baik, terutama dari segi waktunya.

\section{Daftar Pustaka}

[1] Pratama and A. Hadi, "techinasia," 29 November 2016. [Online]. Available: http://id.techinasia.com/indonesia-e-commerce-submmit-expo-2016. [Accessed 6 Agustus 2016].

[2] Y. Syahrul and D. Ameidyo, "Kata Data," 10 November 2016. [Online]. Available: http://katadata.co.id/telaah/2015/12/18/indonesia-pasar-e-commerce-terbesar-di-asean-denganbanyak-kendala. [Accessed 6 Agustus 2016].

[3] Y. A. Pratama, D. Wijaya, Paulus and A. Halim, "Digital Cakery Dengan Algoritma Collaborative Filtering," Teknik Informatika, 2013.

[4] Rio, Oktora, Susanty and Wiwin, "Perancangan Aplikasi E-Commerce Dengan Sistem Rekomendasi Item-Based Collaborative Filltering," Manajemen sistem Informasi Dan Teknologi, 2013.

[5] Xu, Guandong, Zhang, Yanchun, Li and Lin, Web Mining and Social Networking, New York: Springer, 2010.

[6] D. Dwi and Purwanto, "Rekomendasi Paket Pembelian Barang pada Toko Online dengan Collaborative Filering," in Seminar Nasional Sains dan Teknologi Terapan III 2015. Institut Teknologi Adhi Tama, Surabaya, 2015.

[7] S. Uyun, I. Fahrurrozi and A. Mulyanto, "Item Collaborative Filtering untuk Rekomendasi Pembelian Buku secara Online," JUSI, vol. I, no. 1, pp. 64-70, 2011.

[8] M. Irfan, A. D. C and F. H. R., "Sistem Rekomendasi : Buku Online dengan Metode Collaborative Filtering," Teknologi Technoscientia, vol. VII, pp. 76-84, 2014.

[9] H. Susanto, "Perancangan Sistem Rekomendasi Pakaian Distro Dengan Menggunakan Item Collaborative Filtering (Studi Kasus : The Jungle Distro Medan)," Pelita Informatika Budi Darma, vol. VI, no. 3, pp. 58-62, 2014.

[10] J. B. Schafer, D. Frankowski, J. Herlocker and S. Sen, Collaborative Filtering Recommender Systems, Berlin: Springer-Verlag, 2007.

[11] G. Adomavicius and Y. O. Kwon, "New recommendation techniques for multicriteria rating systems," IEEE Intelligent Systems, vol. 22, no. 3, pp. 48-55, 2007. 
[12] A. Purwanto, "Metode Analisis Rekomendasi pada Sistem Rekomendasi (Contoh Kasus Pemanfaatan pada Biro Wisata)," 2009.

[13] Q. Li and B. M. Kim, "An Approach for Combining Content-based and Collaborative Filters," Departement of Computer Sciences, Kumoh NationalInstitute of Technology, 2002.

[14] F. Ricci, L. Rokach and B. Shapira, Recommender Systems Handbook, Springer, 2010. 